\title{
POLÍTICAS DE GESTÃO DE PESSOAS: UM ESTUDO DE CASO SOBRE A PERCEPÇÃO MOTIVACIONAL DOS COLABORADORES DA COOPERATIVA CRESOL DE LARANJEIRAS DO SUL/PR
}

Maria Polliana Gurnaski ${ }^{1}$

Ceyça Lia Palerosi Borges ${ }^{2}$

GURNASKI, M. P.; BORGES, C. L. P. políticas de gestão de pessoas: um estudo de caso sobre a percepção motivacional dos colaboradores da cooperativa Cresol de Laranjeiras do Sul/Pr. Rev. Ciênc. Empres. UNIPAR, Umuarama, v. 21, n. 1, p. 75-99, jan./jun. 2020.

RESUMO: Por meio desta pesquisa buscou-se verificar quais políticas de Gestão de Pessoas podem favorecer a motivação dos colaboradores da Cooperativa Cresol de Laranjeiras do Sul/PR. Para alcançar o objetivo proposto, adotou-se o método de abordagem qualitativo, de caráter exploratório e descritivo. Para a coleta das informações da pesquisa, foi utilizada a análise documental para verificar o Manual de Políticas de Gestão de Pessoas - Colaboradores 2018 do Sistema Cresol, entrevista com a gerente de Recursos Humanos da Cresol Vale das Águas e com os colaboradores da Cresol de Laranjeiras do Sul, para avaliar, se essas políticas contribuem no aspecto motivacional. Diante do objetivo proposto nesta pesquisa foi possível analisar que a Cooperativa Cresol aplica, em grande maioria, suas políticas de Gestão de Pessoas na organização. Além disso, destaca-se que tais políticas podem favorecer na motivação de seus colaboradores, pois foi evidenciada a satisfação e motivação dos funcionários em relação às práticas no trabalho e as políticas organizacionais.

PALAVRAS-CHAVE: Trabalho; Gestão de Pessoas e Práticas Organizacionais.

\section{PEOPLE MANAGEMENT POLITICS: A CASE STUDY ON THE MOTIVATIONAL PERCEPTION OF EMPLOYEES AT CRESOL COOPERATIVE IN LARANJEIRAS DO SUL/PR}

\footnotetext{
ABSTRACT: Through this survey, the authors sought to check which People management policies may favor the motivation of the employees at the Cresol

DOI: $10.25110 /$ receu.v21i1.7467

${ }^{1}$ Graduada em Secretariado Executivo pela Universidade Estadual do Centro Oeste (UNICENTRO) e pós-graduada em Economia Empresarial e Gestão de Pequenos Negócios pela Universidade Federal da Fronteira Sul (UFFS). polliana_gurnaski@hotmail.com

${ }^{2}$ Graduada em Administração pela Universidade Federal de Lavras e mestre em Administração pela Universidade Federal de Lavras. Professora titular da Universidade Federal da Fronteira Sul (UFFS) - campus Laranjeiras do Sul. ceyca.borges@uffs.edu.br
} 
Cooperative in the city of Laranjeiras do Sul in the state of Paraná. In order to reach the proposed intent, a qualitative approach method was adopted, using an exploratory and descriptive character. The information was collected through the analysis of documents to check the People Management Policy Manual for 2018 Employees at the Cresol System (Manual de Políticas de Gestão de Pessoas - Colaboradores 2018 do Sistema Cresol), interviews with the Human Resources Manager at Cresol Vale das Águas and with the employees at Cresol de Laranjeiras do Sul to evaluate if those policies contribute towards motivation. Given the purpose of the survey, it was possible to assert that the Cresol Cooperative applies its People management policies in most of the organization. Additionally, it is important to emphasize that such policies may favor the motivation of its employees, since the employee's satisfaction and motivation towards the practices at work and the organizational policies were evidenced.

KEYWORDS: Work; People Management and Organizational Practices.

\section{POLÍTICAS DE GESTIÓN DE PERSONAS: UN ESTUDIO DE CASO SOBRE LA PERCEPCIÓN MOTIVACIONAL DE LOS COLABORADORES DE LA COOPERATIVA CRESOL DE LARANJERAS DO SUL / PR}

RESUMEN: Por medio de esta investigación se buscó verificar qué políticas de Gestión de Personas pueden favorecer la motivación de los colaboradores de la Cooperativa Cresol de Laranjeiras do Sul / PR. Para alcanzar el objetivo propuesto, se adoptó el método de abordaje cualitativo, de carácter exploratorio y descriptivo. Para la recolección de las informaciones de la investigación, se utilizó el análisis documental para verificar el Manual de Políticas de Gestión de Personas - Colaboradores 2018 del Sistema Cresol, entrevista con la gerente de Recursos Humanos de la Cresol Vale da Aguas y con los colaboradores de Cresol de Laranjeiras do Sul, para evaluar si esas políticas contribuyen en el aspecto motivacional. Ante el objetivo propuesto en esta investigación fue posible analizar que la Cooperativa Cresol aplica, en gran mayoría, sus políticas de Gestión de Personas en la organización. Además, se destaca que tales políticas pueden favorecer en la motivación de sus colaboradores, pues se evidenció la satisfacción y motivación de los funcionarios en relación a las prácticas en el trabajo y las políticas organizacionales.

PALABRAS CLAVE: Trabajo; Gestión de Personas y Prácticas Organizacionales. 


\section{INTRODUÇÃO}

O ambiente de competitividade acirrado em que as empresas encontramse atualmente obriga os gestores adotarem estratégias muito bem elaboradas, visando se destacar diante dos clientes. Na atualidade a organização empresarial vem se preocupando com um novo modelo de Gestão de Pessoas que assegure o funcionamento de suas atividades e garanta resultados mais satisfatórios, seja na prestação de serviços ou no sistema de produção (ARAÚJO; MENDES, 2018). Para isso, esse tipo de gestão deve estar alinhado com o atendimento que supra as necessidades organizacionais, e assim, manter os objetivos individuais de seus colaboradores.

Assim, para resistir à competitividade, é necessário agir de forma que se consiga uma vantagem competitiva sobre os concorrentes. Conforme Dessler (2003), vantagem competitiva é um conjunto de quesitos capazes de fazer com que a organização tenha um diferencial perante os concorrentes. Neste sentido, nota-se que a vantagem competitiva advém de algo que os concorrentes não conseguem ter e investir em pessoas dentro da organização pode ser uma vantagem competitiva. Gonçalves e Probst (2016), explicam que as pessoas precisam se sentir necessárias às organizações e assim, considerar-se vinculadas ao processo de trabalho, e consequentemente produzir melhores resultados estratégicos na organização.

Para Hanashiro, Teixeira e Zacarelli (2007), a gestão de pessoas foi uma das áreas das organizações que sofreu pelas inúmeras transformações no século $\mathrm{XX}$.

Chiavenatto (2010) afirma que as organizações necessitam das pessoas para alcançar seus objetivos. Sendo assim, em um mercado com tantos obstáculos movidos pela competitividade, as empresas precisam manter-se equilibradas diante de seus concorrentes, buscando estratégias em seu recurso mais valioso, as pessoas.

Conforme Gil (2012), o mundo competitivo dos negócios exige que os colaboradores estejam motivados a atuarem na empresa, e quando motivados em seu trabalho, tendem a proporcionar melhores resultados.

Diante desse contexto, essa pesquisa tem como objetivo identificar quais as políticas adotadas pela Gestão de Pessoas na Cooperativa Cresol de Laranjeiras do Sul/PR que favorecem a motivação dos seus colaboradores.

\section{REVISÃO DA LITERATURA}

\subsection{Competitividade organizacional contemporânea}

O atual cenário competitivo econômico é marcado por um processo de 
globalização e a sociedade vem passando por diversos ciclos evolutivos nas áreas da ciência, economia, instituições financeiras e muitos outros (RIBEIRO et al., 2017).

Uma empresa competitiva busca não só sobreviver, mas também, se destacar no mercado por seu desempenho e ser atrativa para seus colaboradores sentirem-se motivados a atuarem. Tal execução depende, antes de tudo, das pessoas e na realidade, grande parte das empresas possui colaboradores não comprometidos, desmotivados e assim, consequentemente com pouca capacidade de adaptação (SASTRE, 2018). Portanto, para que as pessoas sejam capazes de aplicar estratégias assertivas em seu espaço de trabalho, buscando alcançar os objetivos propostos pela empresa, devem estar motivados em seu ambiente organizacional.

Conforme Silva, Marcelino e Silva (2017), mesmo nesse ambiente organizacional de constantes mudanças, ainda há muitos gestores com posturas e práticas inadequadas à realidade e contrárias ao exigente comportamento que precisam perfilhar para se inserirem a esse novo cenário empresarial.

No atual mercado competitivo que exige das organizações adaptação às mudanças, rapidez e eficiência nas decisões, percebe-se a carência de entendimento dos gestores das organizações contemporâneas no que diz respeito à valorização e retenção de conhecimento e capital intelectual dos seus colaboradores com o intuito de ter profissionais motivados e fortalecer seu processo de decisão. Até porque, investir em pessoas se tornou indispensável a qualquer empresa que queira sobreviver, uma vez que, é esse recurso que diferenciará os negócios de sucesso (SANTOS; JESUS; FERREIRA, 2016, p. 102).

O mundo empresarial competitivo exige das empresas que se adaptem à mudança, tomando decisões assertivas para o bom funcionamento do negócio e busquem, cada vez mais, motivar seus colaboradores para que estejam estusiasmados a trabalharem de forma que a organização tenha um fator de competitividade não atingível por outras empresas.

Entende-se como fator de competitividade aquilo que se configura como uma real preocupação e razão de ser de cada atividade da empresa. Essas "razões de fundo" ou "razões de ser" se constituem em aspectos que, ao serem claramente identificados, podem contribuir para o aperfeiçoamento organizacional, ou mais especificamente, 
para o aumento da performance. Pode-se dizer que o fator de competitividade corresponde às variáveis nas quais a organização precisa apresentar bom desempenho, para sobreviver e se destacar em relação ao mercado (ROMAN et al., p. 28, 2012).

Cada empresa precisa apresentar e dispor de quesitos capazes de fazer com que tenha bom desempenho de sobrevivência e ainda se distinguir como melhor no mercado de trabalho.

De acordo com Porter (1998 apud COSTA, 2018), a competitividade é a habilidade dos conhecimentos capazes de criarem um desempenho acima da concorrência. As organizações que atuam no mercado de trabalho defrontam-se com concorrentes diretos e indiretos que podem colocar em risco sua existência. Conforme Chiavenato (2014, apud VIDAL et al., 2018), todas as organizações com fins lucrativos almejam obter um alto retorno sobre o capital que é aplicado. Assim, fazem o uso de diferentes meios para permanecerem à frente dos seus concorrentes, e obterem melhores margens para aumentarem a participação no mercado.

Para tanto, as empresas conseguem ter uma vantagem competitiviva investindo nos seus colaboradores. Conforme Matos (2018, p. 7) “A vantagem competitiva que as organizações obtêm através da qualidade, reflete-se na satisfação dos clientes, por meio do fornecimento de bens/serviços adequados às suas exigências, o que leva o cliente a ter preferência pelo produto".

Compreende-se que investindo nos colaboradores em uma organização e deixando-os motivados a atuarem na empresa, podem ter um melhor desempenho nos resultados e ainda prestarão serviço de melhor qualidade. Além de um bom atendimento, que pode resultar em clientes satisfeitos e que em virtude disso, podem ser consolidados da organização, aumentando os lucros da empresa.

Sendo assim, diante dessa competitividade é de extrema importância que a gestão de pessoas construa estratégias que aborde todos os seus pilares para que consiga de fato um diferencial competitivo.

\subsection{Os pilares da gestão de pessoas}

As empresas devem adotar políticas capazes de atrair e reter bons colaboradores que busquem alcançar junto à organização seus objetivos propostos. Gil (2001 apud MONTEIRO; NASCIMENTO, 2016), diz que a Gestão de Pessoas está relacionada em subsistemas, que constituem um aprimoramento das principais práticas ligadas a área de Gestão de Pessoas.

Neste sentido, a Gestão de Pessoas é dividida em cinco subsistemas, sendo eles: Provisão, Aplicação, Manutenção, Desenvolvimento e Controle. Chiavenato (2010 apud SILVA, 2018), corrobam essa ideia ao dizer que é a área 
que constrói talentos por meio de uma soma de processos agrupados e do capital humano, proporcionando competências e competitividade às organizações.

Conforme Marras (2000 apud MOURO; STEFANO, 2016), o subsistema de Provisão é relativo ao suprimento de pessoas na organização; o de Aplicação está relacionado ao recrutamento, seleção e treinamento; o de Manutenção refere-se ao plano e benefícios que a empresa aplica para manter os funcionários na organização; o subsistema de Desenvolvimento age na elaboração de competências individuais e coletivas, e por fim, o subsistema de Controle proporciona dados sobre a gestão da informação dentro das empresas, auxiliando na tomada de decisões.

De acordo com Rosa (2017), é por meio do subsistema de Provisão que a empresa seleciona os talentos com atributos precisos para que alcance os resultados que a organização espera. Ou seja, o subsistema de Provisão engloba um planejamento dos recursos humanos, um processo capaz de traçar um perfil do colaborador, realizando tarefas dirigidas ao cargo e assim, auxiliar para que alcancem os objetivos de maneira eficiente e eficaz.

Já no processo de Aplicação, abrangem-se as primeiras etapas na integração de novos componentes. Nesse processo a organização define sobre os cargos, suas descrições e análise, além da avaliação de desempenho dos funcionários. Ou seja, é o método utilizado para analisar quais as caracteristicas básicas que uma pessoa precisa ter para desempenhar as atividades que lhes são demandadas (MOREIRA et al., 2017). Assim, quando escolhidas, as pessoas devem ser integradas à organização, direcionadas em seus cargos e avaliadas quanto ao seu trabalho (CHIAVENATO, 2010; DREWS et al,. 2009 apud MOREIRA et al., 2017).

Após o processo de Aplicação, vem o de Manutenção, que se refere à atualização de salário. Chiavenato (2003 apud PORTELLA, et al., 2017) destacam que este aspecto trata da evolução dos cargos, avaliação de desempenho, atualização de sistemas, e outros.

Em sequência vem o processo de Desenvolvimento, o qual diz respeito ao treinamento, desenvolvimento de Recursos Humanos e organizacional.

[...] o quarto é o subsistema de desenvolvimento de recursos humanos que trata do treinamento de pessoal, ou seja, educação profissional que visa adaptar a pessoa ao trabalho em determinada empresa, preparando-o adequadamente para o exercício do cargo e do desenvolvimento organizacional do qual desenvolve um aperfeiçoamento das capacidades e motivações dos empregados a fim de torná-los futuros membros valiosos da organização [...] (PORTELLA; DIAS, 2017, p. 04). 
Então, o subsistema de Desenvolvimento é aquele que adapta o funcionário à organização, de acordo com sua maneira de atuar e deixá-o apto ao cargo que vai desenvolver.

Por fim, conforme Chiavenato (2010 apud BONIFÁCIO, ANJOS 2017, p. 138), "no processo de Monitorar pessoas, incluem-se banco de dados e um sistema de informação gerencial".

Considerando os pilares capazes de recrutar e reter bons funcionários, a Gestão de Pessoas apresenta também suas políticas que são capazes de manter os colaboradores motivados a atuarem em uma organização.

\subsection{Políticas de gestão de pessoas relacionadas à motivação dos colaboradores}

Conforme Martins e Misturini (2017), a política de recompensas diz respeito a uma forma de demonstrar que os colaboradores são essenciais para a organização, além de dar mérito ao seu trabalho desenvolvido. Dessa maneira, a empresa busca reter talentos, quesito essencial para uma organização que procura ter vantagem competitiva.

Felipe (2017, p. 16), enaltece essa ideia ao dizer que "tais recompensas podem ser consideradas como estímulos, cuja falta tende a gerar a sensação de desprestígio por parte dos colaboradores, o que pode acarretar em abatimento na motivação e tornar a organização menos eficaz".

Percebe-se que a motivação dos funcionários pode estar ligada às recompensas que ela recebe da organização, como forma de reconhecimento de seu trabalho desenvolvido. Com políticas de recompensa adequadas às necessidades de cada colaborador, estes podem elevar a empresa a ter vantagem competitiva das demais.

Um novo mercado competitivo faz com que as organizações se reorganizem para enfrentar a demanda da competitividade. Conforme Alves e Ferreira (2018, p. 8):

Estar satisfeito com o trabalho que desempenha, faz com que o colaborador, consequentemente, sinta-se motivado a efetuar suas atividades de maneira mais eficiente. Dessa forma, os resultados alcançados não somente serão mais eficazes, como também estão indo ao encontro dos objetivos de qualquer corporação que almeje maximizar o desempenho de seus colaboradores e obter o melhor rendimento possível em seu ramo de atuação.

Para tanto, é preciso que as empresas estipulem políticas de gestão de pessoas dentro das organizações para que possam manter seus funcionários motivados e assim, garantir vantagem competitiva das demais. A motivação de 
colaboradores é de extrema importância no ambiente dos negócios para que estes atuem de forma eficiente e pró ativa, desempenhando suas funções conforme o almejado pela empresa. De acordo com Macedo (2016 apud SOUZA; ANJOS 2018), em cooperativas de crédito, onde os clientes são os donos do negócio, é de suma importância que os colaboradores estejam motivados a atuarem, para que assim, prestem um excelente atendimento e resulte em bons resultados para os cooperados. De acordo com Barbosa (2017, p. 9), "a motivação é um componente importante na gestão de pessoas, é ela quem irá determinar os níveis de desempenho pessoal e profissional obtidos".

Conforme Santos (2004 apud DEMO et al., 2015), a maneira como a organização se prepara diante do comportamento humano é chamada de modelos de Gestão de Pessoas. "Um dos atuais objetivos da GP é diferenciar a organização frente ao seu mercado, gerando uma contribuição positiva na imagem e na competitividade" (Demo et al., 2015, p. 91).

Portanto, as políticas e práticas de Gestão de Pessoas passaram a não ser uma despesa para as organizações, mas sim, podem ser a vantagem competitiva da empresa, uma vez que funcionários motivados perfilados com os objetivos corporativos se tornam ativos valiosos no atual ambiente concorrencial. Conforme Silva et al., (2018), as empresas devem saber idealizar e executar políticas e práticas de maneira competente que façam com as orgazizações tenham sucesso e garantam um bom desempenho e crescimento no mercado. Assim, os gestores de pessoas devem complementar o desempenho dos colaboradores, e, também em consequência, das organizações.

Demo et al., (2012 apud JESUS, 2016) verificando a lacuna de instrumento para análise das percepções sobre políticas de gestão de pessoas, desenvolveram e regularizaram a Escala de Políticas de Gestão de Recursos Humanos, abrangendo as seguintes práticas de gestão de pessoas: Recrutamento e Seleção, Envolvimento, Treinamento, Desenvolvimento e Educação, Condições de Trabalho, Avaliação de Desempenho e Competências e Recompensas.

No Quadro 1.1 são apresentadas as definições construtivas de cada uma das práticas: 
Quadro 1: Cadeia causal das políticas de gestão de pessoas

\begin{tabular}{|l|l|}
\hline Prática de Gestão de Pessoas & Definição \\
\hline Recrutamento e seleção & $\begin{array}{l}\text { Procurar colaboradores, estimulá-los a se candidatar e selecioná- } \\
\text { los, buscando harmonizar valores, interesses, expectativas e } \\
\text { competências da pessoa com as características e demandas do } \\
\text { cargo e da organização. }\end{array}$ \\
\hline Envolvimento & $\begin{array}{l}\text { Criar um vínculo afetivo com seus colaboradores, contribuindo } \\
\text { para o seu bem-estar no trabalho, em termos de reconhecimento, } \\
\text { relacionamento, participação e comunicação. }\end{array}$ \\
\hline $\begin{array}{l}\text { Treinamento, desenvolvimento e } \\
\text { educação }\end{array}$ & $\begin{array}{l}\text { Fornecer meios para a aquisição de competências sistemática } \\
\text { dos colaboradores e para estimular a aprendizagem contínua e } \\
\text { produção de conhecimento. }\end{array}$ \\
\hline Condições de trabalho & $\begin{array}{l}\text { Fornecer aos funcionários boas condições de trabalho em termos } \\
\text { de benefícios, saúde, segurança e tecnologia. }\end{array}$ \\
\hline Avaliação de desempenho e competências colaborador, \\
\hline Recompensas & $\begin{array}{l}\text { Avaliar o desempenho e a competência do colaborando decisões sobre promoções, planejamento de carreira e } \\
\text { apoiando } \\
\text { desenvolvimento. }\end{array}$ \\
\hline
\end{tabular}

Fonte: Demo, G., Neiva, E. R., Nunes, I., \& Rozzett, K. (2012). Human resources management policies and practices scale (HRMPPS): Exploratory and confirmatory factor analysis. BARBrazilian Administration Review, 9(4), 395-420, apud Jesus 2016.

Mostra-se a seguir, por meio de estudos, como tais práticas podem influenciar na motivação dos colaboradores na organização. Conforme Dutra (2002 apud MENDES, 2017), a motivação no espaço corporativo e também o reconhecimento são razões significativas no que diz respeito ao incentivo profissional, que assim, pode-se obter um ambiente de trabalho com melhor desempenho das tarefas individuais. Por isso, as práticas de gestão de pessoas podem ser um elo entre a motivação dos colaboradores e os bons resultados para a organização.

Marras (2014 apud CATANEO, 2016), diz que o processo de Recrutamento acaba sendo o mais conveniente para as empresas, porque é um grande mecanismo motivacional, tendo em vista a potencialização do tempo ao longo do andamento e o custo é baixo. Dantas (2018) complementa que os procedimentos de Recrutamento e Seleção podem ser empregados tanto internamente quanto externamente, sendo que as duas opções tem por objetivo atrair os candidatos mais qualificados para ocuparem uma vaga.

Já o processo de Envolvimento, conforme Fleury; Oliveira Junior (2002 apud VIEIRA et al., 2013), é onde se desenvolve novas habilidades e que pode resultar a compreensão das pessoas sobre a realidade. "O processo de capacitação é uma necessidade da organização que eleva o desempenho profissional e a motivação dos trabalhadores", (VIEIRA et al., 2013, p. 204). Assim, percebe-se que tal processo serve para unir o novo funcionário junto à empresa, potencializando suas competências e fazer com que o colaborador entenda sobre o funcionamento da organização. 
Após o processo de Envolvimento, vem o de Treinamento, que de acordo com Vizoli (2010 apud YAMAUCHI, 2017, p. 37):

A fase de treinamento e desenvolvimento tem ganhado cada vez mais espaço nas organizações, pois, além de evidenciarem a elevação da capacidade do colaborador, também estão intrinsecamente relacionados à motivação, uma vez que servem como forma de reconhecimento do valor das pessoas para a organização e também da qualidade do clima organizacional, representando um desafio e uma saudável quebra na rotina.

Esse processo caracteriza-se pelo suporte que a empresa dá ao novo colaborador, capacitando-o para cumprir com suas devidas atribuições.

E para que esse funcionário trabalhe em um ambiente adequado, a gestão de pessoas apresenta o processo de Condições de Trabalho, que envolve a saúde, tecnologia e segurança.

No ambiente organizacional, a motivação é tratada sob a observância do comportamento humano, desafiando o gestor a encontrar meios de motivar os empregados a realizar suas atividades com satisfação, garantindo a produtividade. $\mathrm{O}$ gestor organizacional deve incentivar a motivação, identificando em seus liderados, suas necessidades prementes, e diligenciando o ambiente laboral, de maneira a melhorar as condições de trabalho (SILVA, 2017, p. 23).

Ou seja, a organização deve oferecer condições de trabalho adequadas para que o funcionário desenvolva de maneira eficaz suas atividades e também, garanta sua satisfação pessoal no que diz respeito a sua segurança e saúde.

Após esses processos de adequar o colaborador à empresa, é o momento de realizar a Avaliação de Desempenho para mensurar suas competências. Almeida (1996, p. 19 apud COSTA, 2017, p. 33), cita os principais objetivos da avaliação de desempenho. "Melhorar a produtividade, motivação e desenvolvimento das capacidades pessoais; auxiliar nas decisões de organização e gestão pessoal (salários, prêmios, promoções, transferências, etc.); identificar candidatos potenciais para funções de maior responsabilidade; escolha de critérios de seleção e treino". Assim, pode-se verificar que a avaliação de desempenho está ligada com todo o contexto organizacional, tendo em vista que é um elo com as demais práticas da gestão de pessoas, e assim podem interferir nos demais processos. 
E por fim, vem o processo de Recompensa, o qual se remete a gratificar o desempenho e a competência dos colaboradores por meio de remunerações e incentivos. Conforme Mendes, 2017, p. 26, “A recompensa é um elemento indispensável para o sucesso de um plano de gestão de recursos humanos, pois ele está no centro do processo motivacional do profissional, além de ser um processo que necessita flexibilidade". Varela $(2017$, p. 06) complementa que "A falta de recompensas irá criar desmotivação, com a consequente redução do desempenho do colaborador. Por essas razões as recompensas são cada vez mais importantes".

Camara (2011, p. 69, apud VARELA 2017, p. 6) corroba ainda que "na sociedade do conhecimento que estamos mergulhados, não se pode gerir bem as competências sem uma boa gestão de recompensas". Para Chiavenato, (2004, apud AGUSTINI, et al., p. 02: "a recompensa das pessoas dentro das organizações constitui um dos elementos fundamentais para o incentivo e a motivação dos colaboradores.

Sendo assim, existem duas formas diferentes de recompensar pessoas, que de acordo com Chiavenatto (2014, apud NYARADI, 2016), uma delas é a abordagem tradicional, que subtende que os colaboradores são motivados apenas por incentivos salariais, financeiros e materiais. E também a abordagem moderna, a qual considera que a motivação dos funcionários advém de diversas formas de incentivos, como salário, objetivos, metas a cumprir, satisfação, necessidade de se sentirem realizados.

Portanto há duas formas de recompensar pessoas, sendo elas financeiras e não financeiras. Segundo estudo de Hanashiro (2008 apud NYARADI, 2016, p. 23), "as estratégias financeiras e não financeiras são as diferentes modalidades acessíveis que as organizações podem aplicar para gratificar seus funcionários".

Desta forma, percebe-se que as organizações precisam agregar as duas maneiras de recompensas para motivar da melhor maneira possível seus colaboradores.

E sobre as recompensas não financeiras, conforme Hanashiro (2008, apud NYARADI, 2016), é o que interfere diretamente o desempenho dos colaboradores, pois a empresa facilita para que seus funcionários sejam reconhecidos, e tenham também, qualidade de vida no ambiente corporativo.

Sendo assim, pode-se destacar que colaboradores motivados com seu retorno compensatório pode gerir melhores resultados para a organização, uma vez que o salário é apenas item básico para retribuir seu trabalho desenvolvido, mas somente esta prática não é a única forma de mantê-lo motivado.

\section{PROCEDIMENTOS METODOLÓGICOS}

Com o objetivo de verificar quais as políticas da gestão de pessoas 
que os colaboradores da Cooperativa Cresol de Laranjeiras do Sul consideram importantes para ter motivação no ambiente de trabalho, esta pesquisa utilizou da abordagem qualitativa descritiva e de caráter exploratório. De acordo com Marconi; Lakatos (2011), a pesquisa qualitativa vai fornecer uma análise detalhada sobre investigações e hábitos de uma população, etc. Já o caráter descritivo da pesquisa possibilita identificar as características de uma população, por exemplo, (BOAVENTURA, 2007) e a exploratória torna o problema mais explícito (GIL, 2012).

A técnica de coleta de dados desse estudo se baseia em um estudo de caso, aplicado na Cooperativa Cresol de Laranjeiras do Sul. Conforme Golsalves (2007, p. 69) "[...] é o tipo de pesquisa que previlegia um caso particular, uma unidade significativa, considerada suficiente para análise de um fenômeno".

Os instrumentos de coleta de dados foram por meio de análise documental, através do Manual de Políticas de Gestão de Pessoas - Colaboradores 2018 do Sistema Cresol, para verificar se a cooperativa possui políticas de gestão de pessoas que podem contribuir na motivação de seus colaboradores. Segundo Roesch (2010), a análise documental possibilita o entendimento de situações ppor meio de documentos elaborados e mantidos pela empresa. E também foi aplicado um roteiro de entrevista com a gerente de Recursos Humanos da cooperativa para analisar se tais políticas descritas no Manual são aplicadas no dia a dia da empresa. Além disso, a pesquisa conta também com as entrevistas semiestruturadas aplicadas aos colaboradores que fazem parte do atendimento da Cooperativa Cresol de Laranjeiras do Sul para mensurar, se de fato, eles se sentem motivados com tais políticas. Conforme Markoni e Lakatos (2011, p. 178: "A entrevista é um encontro entre duas pessoas, a fim de que uma delas obtenha informações a respeito de determinado assunto [...]."

Quanto à análise dos dados, foi utilizado o método de análise de conteúdo. Conforme Silva e Fossá, $(2015$, p. 2) “A análise de conteúdo é uma técnica de análise das comunicações, que irá analisar o que foi dito nas entrevistas ou observado pelo pesquisador".

\section{RESULTADOS E DISCUSSÃO}

\subsection{Caracterização dos entrevistados}

No Quadro 2 é possível analisar o perfil de cada participante, demonstrando suas formações, área e tempo de atuação na Cooperativa Cresol. 
Quadro 2: Perfil dos entrevistados:

\begin{tabular}{|c|l|l|l|}
\hline Sujeito & \multicolumn{1}{|c|}{ Formação } & \multicolumn{1}{c|}{ Área de atuação } & \multicolumn{1}{c|}{ Tempo de atuação } \\
\hline Sujeito 1 & Ciências Econômicas & Caixa e assistente de negócios & 1 ano e 9 meses \\
\hline Sujeito 2 & Administração & Analista de crédito & 1 ano e 5 meses \\
\hline Sujeito 3 & Mestre em Educação & Conselheiro secretário & 23 anos \\
\hline Sujeito 4 & Ciências Contábeis & Assistente de negócios & 8 meses \\
\hline Sujeito 5 & Gestão de Agronegócios e Pedagogia & Analista de negócios & 14 anos \\
\hline
\end{tabular}

Fonte: Elaborada pelas autoras, 2018.

Dos oito colaboradores que fazem parte do setor de atendimento da Cooperativa Cresol de Laranjeiras do Sul, cinco responderam o roteiro de entrevista, sendo que três deles não conseguiram responder a tempo hábil para análise das respostas. Todos os funcionários entrevistados tem formação em nível de graduação. Além disso, pode notar que dois colaboradores tem tempo maior de atuação na empresa e três tem menos tempo.

\subsection{Políticas descritas no Manual de Gestão de Pessoas e análise das respostas da gerente de Recursos Humanos}

Neste item demonstram-se as políticas da gestão de pessoas documentadas no Manual e Políticas de Gestão de Pessoas - Colaboradores 2018 para as Entidades do Sistema Cresol, bem como as análises das respostas da gerente de Recursos Humanos, fazendo as considerações entre a teoria e a prática de como tais políticas funcionam.

Conforme o Manual de Políticas de Gestão de Pessoas - Colaboradores 2018 para as Entidades do Sistema Cresol, no item de Recrutamento e Seleção, o objetivo é estabelecer diretrizes e critérios que viabilizem os processos de recrutamento e seleção visando atrair profissionais com capacidade para agregar valor e sintonizar com a missão, visão e valores das Entidades do Sistema Cresol Baser. Esse processo, conforme o Manual, pode ser interno ou externo. Neste sentido, a descrição do manual faz uma analogia com a visão do autor Dantas (2018), o qual diz que os procedimentos de recrutamento e seleção podem ser empregados tanto internamente quanto externamente, sendo que as duas opções tem por objetivo atrair os candidatos mais qualificados para ocuparem uma vaga.

De acordo com análise das respostas da gerente de Recursos Humanos da cooperativa, nota-se que tal diretriz descrita no Manual está concordante com a realidade da empresa. Analisando que há o recrutamento e seleção interno e externo, a pesquisa buscou compreender através de perguntas à gerente de RH se a Cooperativa Cresol verifica que existe a possibilidade de desmotivar e frustrar o crescimento da equipe e a probabilidade de causar desajustes na política salarial da organização no caso de usar o método interno. Conforme a gerente, o objetivo é que não haja aspectos negativos neste processo. "No recrutamento e seleção 
ocorre a avaliação de currículo, perfil, conhecimento técnico, etc. [...] desde o início de todo o processo seletivo busca-se valores condizentes com a empresa. Além disso, em se tratando de pessoas, todo caso precisa ser analisado pois há peculiaridades. Buscamos dar oportunidades internas de acordo com as vagas para que não haja desmotivação dos nossos colaboradores. O objetivo é que o processo não gere nenhum impacto negativo", explica a gerente.

Em relação à política de Envolvimento no Trabalho, o Manual de Políticas diz que ao selecionar um novo colaborador para atuar em uma agência da Cresol, o objetivo é fazer com que essa pessoa se sinta envolvida nas ações da cooperativa. Conforme destaca a gerente de $\mathrm{RH}$, tal processo é aplicado através de programas de reconhecimento por tempo de empresa, feedback das atividades, confraternizações, etc. "Sem dúvidas é um processo muito importante para mantermos os colaboradores envolvidos com a empresa" [...], cita a gerente. Desta maneira, tal política aplicada pelo RH da Cooperativa Cresol condiz com o conceito descrito por Fleury (2002 apud VIEIRA et al., 2013) ao mencionar que essa política desenvolve novas habilidades aos colaboradores e que pode resultar na melhor compreensão do ambiente corporativo. Percebe-se, assim, que o departamento de Recursos Humanos da Cooperativa Cresol busca desenvolver habilidades necessárias para que os colaboradores se envolvam nas ações da empresa, oferecendo-lhes capacitações necessárias para o trabalho.

Já na política de Treinamento e Desenvolvimento, o Manual de Políticas de Gestão de Pessoas - Colaboradores 2018 da Cresol diz que busca construir programas que sejam capazes de capacitar seus funcionários para que possam desenvolver suas atividades técnicas no dia a dia organizacional. A gerente afirma: "Consideramos que esta integração e/ou adequação do colaborador à empresa é um desafio constante, pois o objetivo da cooperativa é sempre manter seus colaboradores capacitados e qualificados para que prestem um bom atendimento ao associado, consigam alcançar as metas propostas e assim, possam ter melhores recompensas. É por meio de treinamentos como Integração de Novos Colaboradores, Educação à Distância (EAD), reuniões e principalmente por meio dos gestores imediatos que esse conhecimento é repassado aos funcionários". Pode-se contrastar com a explicação de Vizoli (2010 apud YAUMAUCHI, 2018), onde enaltece que essa fase de Treinamento e Desenvolvimento vem recebendo mais espaço nas empresas, pois eleva a competência do colaborador, contribuindo, assim, com sua capacitação profissional.

No quesito Condições de Trabalho, não há tal especificação no Manual de Políticas de Gestão de Pessoas, porém a gerente cita que a cooperativa disponibiliza de meios que são capazes de proporcionar o bem estar de seus colaboradores. "Oferecemos como benefícios aos colaboradores: vale alimentação, seguro de vida, previdência privada, plano de saúde. Todos eles geram bem estar. Sobre 
a segurança, temos um setor que cuida especificamente disso nas agências", lembra a gerente. Para tanto, conforme Silva (2017) é necessário entusiasmar os colaboradores, visando que, através das boas condições de trabalho, estes se sintam motivados a atuarem na organização.

No item Avaliação de Desempenho, o Manual de Políticas tem muito bem estruturado a forma de aplicação. Conforme o item 4.2.1, esta tem por intuito avaliar e diagnosticar o desempenho individual de cada colaborador para desenvolvimento pessoal e profissional, possibilitando colher informações para tomada de decisões a serem desenvolvidas em nível de Sistema. E o item 4.2.3.1 demostra que é aplicada em três etapas: colaborador realiza sua autoavaliação, assessor/gerente/coordenador avalia os colaboradores de sua equipe e também realiza sua própria autoavaliação, conselheiros, gerentes regionais ou assessores serão responsáveis por avaliar os gerentes nos casos onde não há instituído um gerente na equipe, estes avaliarão a mesma. E conforme cita a gerente: "Temos uma busca constante de feedback entre colaborador e empresa".

Almeida (1996, p. 19 apud COSTA, 2017, p. 33) explica que, a avaliação de desempenho serve para "melhorar a produtividade, motivação e desenvolvimento das capacidades pessoais; auxiliar nas decisões de organização e gestão pessoal (salários, prêmios, promoções, transferências, etc.); identificar candidatos potenciais para funções de maior responsabilidade; escolha de critérios de seleção e treino". Portanto, a avaliação de desempenho aplicada na Cooperativa Cresol possibilita que todos os funcionários sejam avaliados em seus conhecimentos técnicos e decisões, oferecendo, desta forma, a valorização dos colaboradores por meio do acompanhamento de suas atividades realizadas, além de melhoria contínua de pontos que precisam ser melhorados.

A última política descrita é a de Recompensa, onde o Manual de Políticas traz definição sobre salário e benefícios oferecidos aos colaboradores. Conforme o item 3.1, os colaboradores que atuam nas organizações do Sistema Cresol devem sentir-se estimulados a traçarem planos de desenvolvimento e participarem de avaliações para ocuparem outras posições.

Conforme destaca a gerente de RH, além da remuneração mensal, os funcionários também recebem outras recompensas como forma de motivá-los, como por exemplo, o Prêmio de Participação nos Resultados (PPR), que de acordo com a profissional, o PPR busca premiar os colaboradores a partir de atingimento de metas estabelecidas e é uma forma de remunerar o esforço dos funcionários durante o ano de trabalho. Além de vale transporte, vale alimentação, seguro de vida, plano de saúde, entre outros. A gerente cita: "Não é só a remuneração mensal que é capaz de motivar os colaboradores, mas a busca de um ambiente de trabalho onde se sintam valorizados também faz parte dessa motivação. É uma junção de vários fatores, muito além do financeiro. Consideramos a honra 
à marca Cresol, ambiente de trabalho, sentir-se pertencente, gostar do que faz, entre outros", exemplifica a gerente.

Desta maneira, tal forma de atuação da Cooperativa Cresol assemelhase com a descrição de Mendes (2017, p. 26): “A recompensa é um elemento indispensável para o sucesso de um plano de gestão de recursos humanos, pois ele está no centro do processo motivacional do profissional [...]".

E ainda questionada sobre quais são as maneiras adotadas pela Cooperativa Cresol para gratificar seus funcionários e que assim, pode mantêlos motivados, a gerente cita: "através de todos os benefícios, além da busca de um ambiente de trabalho aonde se sintam valorizados". Varela $(2017$, p. 06) diz que "A falta de recompensas irá criar desmotivação, com a consequente redução do desempenho do colaborador. Por essas razões as recompensas são cada vez mais importantes". E por fim, a gerente ressalta sobre as ações que são capazes de manter os colaboradores motivados: "É uma junção de vários fatores, muito além do financeiro. Consideramos a honra à marca Cresol, ambiente de trabalho, sentir-se pertencente, gostar do que faz, entre outros".

Desta forma, pode-se inferir que há políticas da gestão de pessoas que podem ser melhores trabalhadas na Cooperativa Cresol para que aumente o nível motivacional de seus colaboradores, como exemplo é a política de Condições de Trabalho, a qual não tem descrição específica no Manual das Políticas da empresa e portanto, não se explica de quais formas que a cooperativa busca oferecer boas condições de trabalho aos seus colaboradores. De maneira oposta, pode-se destacar que as demais políticas da gestão de pessoas mencionadas no referencial teórico desta pesquisa estão descritas no Manual da Cooperativa Cresol e o departamento de Recursos Humanos busca trabalhar perfiladamente com o que está descrito na teoria e o que deve ser aplicado na prática do dia a dia organizacional.

\subsection{As políticas de Gestão de Pessoas da Cooperativa Cresol relacionadas à motivação dos colaboradores}

Neste item apresentam-se quais as respostas dos cinco colaboradores em relação às políticas de Recursos Humanos que são capazes de mantê-los motivados a atuarem na Cooperativa Cresol de Laranjeiras do Sul, bem como uma análise da teoria, da descrição do Manual das Políticas e um contraponto com as respostas dos funcionários.

No que diz respeito ao Reconhecimento, há um consenso nas respostas dos colaboradores, destacando que a Cooperativa Cresol é comprometida em conceber vantagens pelo trabalho desenvolvido por seus funcionários. $\mathrm{O}$ entrevistado 01 relata: "Somos reconhecidos tanto pelo plano de carreira quanto pessoal. Por exemplo, se ao final do ano tem sobras, os colaboradores recebem 
Programa de Participação de Resultados (PPR), clube de excelência, entre outros". O entrevistado 02 complementa: "Por meio de premiações e elogios, a cooperativa mantém o reconhecimento do trabalho que prestamos". Conforme Dutra (2002 apud MENDES, 2017), a motivação no espaço corporativo e também o reconhecimento são razões significativas no que diz respeito ao incentivo profissional, que assim, pode-se obter um ambiente de trabalho com melhor desempenho das tarefas individuais. Por isso, as práticas de gestão de pessoas podem ser um elo entre a motivação dos colaboradores e os bons resultados para a organização. Tal método de reconhecimento que a Cooperativa Cresol aplica na empresa é de fato, conforme respostas dos colaboradores, fator motivacional para o desenvolvimento de suas atividades na organização.

Já em relação ao quesito Relacionamento, os entrevistados destacam que a cooperativa procura sempre ter uma boa relação com a equipe por meio de cursos, reuniões, confraternizações, entre outros. Além disso, ambos mencionam que a cooperativa envolve suas famílias nos eventos da empresa. O entrevistado 03, por exemplo, cita: "Nós somos capacitados para atuarmos na Cresol, desde integração e também há um relacionamento com nossas famílias".

No que diz respeito à Participação, os entrevistados mencionam que os encontros com colaboradores são um quesito primordial. De acordo com o entrevistado 04: "O que soma na participação é que sempre a cooperativa busca englobar as agências de relacionamento e administrativo na maior parte das atividades". Conforme Fleury et al., (2002 apud VIEIRA, et al., 2013), envolver os colaboradores à organização resulta em novas habilidades e pode resultar na compreensão das pessoas sobre a realidade.

Na política de Envolvimento, os colaboradores destacam que é muito bem disseminado, principalmente pelos meios eletrônicos, além das reuniões e informativos. E questionados se o desempenho profissional está relacionado com o envolvimento com a organização, todos os respondentes citam que sim. A entrevistada 05 enaltece:

Nosso desempenho profissional depende muito do envolvimento de nossos gerentes, diretores uma vez que isso vai interferir diretamente no nosso dia a dia de trabalho, dependendo da forma com que eles conduzirem o trabalho pode afetar no desempenho da equipe.

Segundo o entrevistado 01: "A motivação de ser melhor todo dia depende da visão que tenho sobre meu trabalho e como estou desenvolvendo". Isso confere com a ideia do autor Vieira (2013), quando destaca que o envolvimento com a empresa é uma necessidade que eleva o desempenho profissional e a motivação dos colaboradores. 
De acordo com as respostas dos colaboradores, pode-se notar que a política de envolvimento é, de fato, aplicada por meio de cursos online internos e que também são exigidos para promoção profissional. Os entrevistados mencionam que tudo começa pela integração de colaboradores com carga de 40 horas e que mensalmente devem fazer ao menos três cursos de aperfeiçoamento. "A Cresol capacita os novos colaboradores quando começam a atuar em uma das agências e posteriormente vamos fazendo cursos de aperfeiçoamento. Isso nos motiva, pois a empresa demostra que se preocupa com nosso desenvolvimento profissional", destaca o entrevistado 02. Outro ponto destacado pelos entrevistados é que o conhecimento também advém da observação no trabalho de outros colaboradores. Desta forma, pode-se perceber uma conexão com a teoria de Vizoli (2010 apud YAMAUCHI 2018), quando diz que a fase de treinamento está relacionada com a motivação dos colaboradores, pois serve como forma de reconhecimento.

No quesito Condições de Trabalho um dos colaboradores enaltece que a cooperativa deveria ter um vigilante, que assim, poderiam ter mais segurança. Conforme cita Silva (2017, p. 23): "O gestor organizacional deve incentivar a motivação, identificando em seus liderados, suas necessidades prementes, e diligenciando o ambiente laboral, de maneira a melhorar as condições de trabalho".

Ao analisar as respostas dos colaboradores, pode-se notar que a Avaliação de Desempenho os motiva a melhorarem a performance profissional. Um dos entrevistados enaltece: "É nesse momento que passamos a discutir as melhorias para nosso futuro profissional. A avaliação de desempenho nos motiva, pois analisamos o que estamos fazendo de forma correta e procuramos melhorar pessoalmente e profissionalmente". Outro entrevistado complementa: "a avaliação de desempenho nos ajuda a ver onde estamos falhando e onde estão as divergências de opinião para melhorarmos. Isso é fator motivacional para nossa carreira". Dentre outros objetivos da avaliação de desempenho, Almeida (1996, p. 19 apud COSTA, 2017, p. 33), cita que "Melhorar a produtividade, motivação e desenvolvimento das capacidades pessoais", são alguns fatores essenciais dessa política.

Analisando as respostas dos entrevistados, pode-se notar que a recompensa salarial não é único fator motivacional, pois os mesmos citam que outros fatores também podem motivá-los, como: reconhecimento profissional, promoção de cargo, Programa de Participação nos Resultados, auxílio pósgraduação. Um dos entrevistados cita: "O salário não é fator principal. Por exemplo, quando temos reconhecimento do nosso trabalho, sempre buscamos melhorar e assim, o fator financeiro vem junto".

Para tanto, pode-se perceber que o Manual de Políticas de Gestão de 
Pessoas da Cooperativa Cresol não é completo em relação ao que os autores da presente pesquisa dizem sobre as políticas que podem motivar os colaboradores. Faltam itens explicativos das Condições de Trabalho e Envolvimento com os colaboradores. Para tanto, pôde-se analisar que todos os itens descritos no Manual, de acordo com a gerente, são aplicados na organização, porém na visão dos colaboradores ainda há itens que precisam ser melhorados.

\section{CONSIDERAÇÕES FINAIS}

Diante do objetivo de identificar quais as políticas adotadas pela Gestão de Pessoas na Cooperativa Cresol de Laranjeiras do Sul/PR que favorecem a motivação dos seus colaboradores, foi possível perceber e analisar como tais políticas funcionam e como são aplicadas na organização.

A partir da análise documental, entrevistas com a gerente de Recursos Humanos e cinco colaboradores da agência, constata-se que a cooperativa tem uma documentação bem elaborada sobre as políticas de RH e a maioria delas, são de fato aplicadas.

Por meio da pesquisa pode-se inferir que o departamento de Recursos Humanos da Cooperativa Cresol busca praticar as políticas de Gestão de Pessoas no ambiente organizacional da agência de Laranjeiras do Sul, e desta forma, evidencia-se que os colaboradores, em grande maioria, se sentem motivados com tais políticas.

Destaca-se que desde o recrutamento e seleção, a cooperativa já busca por profissionais com habilidades técnicas para desenvolver as funções na empresa, e subsequente a isso, a organização capacita seus colaboradores para que desenvolvam bom atendimento aos cooperados e também tenham motivação para aturem no ambiente de trabalho.

Uma das políticas mais citadas pelos entrevistados foi sobre o Programa de Participação nos Resultados (PPR), ainda os auxílios como de pós-graduação. Além disso, outro ponto destacado como importante para os funcionários é a oportunidade de crescimento profissional dentro da organização.

Os colaboradores destacam também o que pode ser melhorado na cooperativa para que se sintam mais motivados, como por exemplo, a disponibilização de um segurança na agência, visando à segurança de todos os funcionários no ambiente organizacional. Dessa forma, sugere-se que seja acrescentado no Manual de Políticas de Gestão de Pessoas da cooperativa um item sobre Segurança.

Conseguiu-se atingir o objetivo proposto no início dessa pesquisa, tendo em vista que as políticas adotadas pela Gestão de Pessoas no Sistema Cresol são capazes de manter seus colaboradores motivados na organização. Para tanto, a 
presente pesquisa poderia ter abrangido na entrevista todos os colaboradores da Cooperativa de Laranjeiras do Sul, para que o trabalho ficasse mais completo. Além disso, é importante destacar que futuras pesquisas podem ser realizadas nas nove agências da Cresol Vale das Águas, a fim de mensurar o grau satisfatório de todos os colaboradores do sistema Cresol acerca das políticas de gestão de pessoas.

\section{REFERÊNCIAS}

AGUSTINI, Maria Julia. et al. Incentivos organizacionais: a chave do sucesso para o novo sistema de gestão. In: SEMINÁRIO CIENTÍFICO DA FACIG: SOCIEDADE, CIÊNCIA E TECNOLOGIA, 3, Manhuaçu. Anais... Manhuaçu, 2018.

ARAÚJO, Ícaro Matheus Cunha; MENDES, Denise Figueiró. Gestão de pessoas e fidelização de funcionários: um estudo comparativo entre duas redes supermercadistas da cidade de Boa Vista-RR. Revista de Administração de Roraima - UFRR, Boa Vista, v. 8, n. 1, p. 5-27, 29 jun. 2018.

BARBOSA, Rosana Rodrigues. Motivação do trabalhador bancário: estudo de caso em um banco público. 2017. Disponível em: http://ri.unir.br/jspui/ bitstream/123456789/1781/1/ROSANA\%20RODRIGUES\%20BARBOSA.pdf. Acesso em: 19 out. 2019.

BOAVENTURA, Edivaldo. Metodologia da Pesquisa: Monografia, dissertação, tese. São Paulo: Atlas, 2007.

VIDAL, Bianca dos Santos; SOUZA, Jennifer Spigariol de; RIBEIRO, Paulo Eduardo. Capital humano: um diferencial competitivo. Revista Observatório da Economia Latino Americana, fev. 2018. Disponível em: http://www. eumed.net/2/rev/oel/2018/02/capital-humano.html. Acesso em: 19 out. 2019.

BONIFÁCIO, Adriana Aparecida Braz; ANJOS, Mayara Abadia Delfino. Processo de gestão de recursos humanos em uma instituição de ensino superior (IES) privada: estudo de caso na Fundação Carmelitana Mario Palmerio.

Revista GeTeC, v. 6, n. 11, p. 130-145, 2017.

CATANEO, Deisiane Vicente dos Santos. Fatores determinantes na motivação dos colaboradores de uma empresa familiar localizada no município de Urussanga-SC. Revista Foco, v. 10, n. 2, p. 278-296, 2017. 
CHIAVENATO, Idalberto. Gestão de Pessoas. 3. ed. Rio de Janeiro: Elsevier, 2010.

COSTA, Aquilino Manuel Felizardo. Desenvolvimento de um modelo multimetodológico tridimensional de avaliação de desempenho organizacional: competitividade, gestão estratégica e produtividade. 2018. Disponível em: http://dspace.uevora.pt/rdpc/bitstream/10174/23430/1/ Doutoramento $\% 20 \% 20$ Gest $\%$ C3\%A30\%20-\%20Estrat $\%$ C3\%A9gia $\% 20-\% 20$ Aquilino\%20Manuel $\% 20$ Felizardo $\% 20$ Costa $\% 20-\% 20$ Desenvolvimento $\% 20$ de $\% 20$ um $\% 20$ modelo $\% 20$ multimetodol $\% \mathrm{C} 3 \% \mathrm{~B} 3$ gico $\% 20$ tridimensional $\% 20$ de $\% 20$ avalia $\%$ C3\%A7\%C3\%A3o \%20de $\% 20$ desempenho\%20organizacional.... pdf. Acesso em: 19 out. 2018.

DA COSTA, Patrícia Alexandra Pinho. (Re) pensar a avaliação de desempenho: uma proposta de intervenção numa empresa de engenharia. 2017. Disponível em: https://repositorio-aberto.up.pt/ bitstream/10216/109368/2/234841.pdf. Acesso em: 28 out. 2018.

DANTAS, Felipe Rocha. Engajamento e motivação no trabalho: um estudo com os docentes do Instituto Federal de Educação, Ciência e Tecnologia do Norte de Minas Gerais-UFNMG. 2018. Disponível em: https://repositorio. ufba.br/ri/bitstream/ri/25757/1/Disserta\%C3\%A7\%C3\%A3o\%20de $\% 20$ Mestrado\%20-\%20Felipe\%20Rocha\%20Dantas.pdf. Acesso em: 25 out. 2018.

JESUS, Silvia Manoela Santos de; SANTOS, Joana Darc Estrela dos; FERREIRA, Thales Brandão. Inovação na Gestão de Pessoas: Uma abordagem sobre inteligência organizacional. Revista de Negócios ReAGES, v. 1, n. 1, p. 99-122, 2017.

DEL MOURO, Gisele Cristina Fogaça; STEFANO, Silvio Roberto. Práticas de Gestão de Pessoas nas Organizações do Ramos de Concessionárias de automóveis. Revista Eletrônica Científica do CRA-PR-RECC, v. 4, n. 1, p. 20-31, 2017.

DEMO, Gisela; FERNANDES, Thais; FOGAÇA, Natasha. A influência dos valores organizacionais na percepção de políticas e práticas de gestão de pessoas. REAd. Revista Eletrônica de Administração, Porto Alegre, v. 23, n. 1, p. 89-117, 2017.

DESSLER, Gary. Administração de Recursos Humanos. 2. ed. São Paulo: 
Prentice Hall, 2003.

FELIPE, Jorgean Lucas das Chagas. Fatores de motivação dos colaboradores do sindicato dos oficiais alfaiates, costureiras e trabalhadores na indústria de confecção de roupas no estado do Rio Grande do Norte. 2017. Trabalho de Conclusão de Curso. Universidade Federal do Rio Grande do Norte. Disponível em: https://monografias.ufrn.br/jspui/bitstream/123456789/6348/1/ JorgeanLCF_Monografia.pdf. Acesso em: 13 out. 2018.

FERREIRA, Leonardo Rodrigues; ALVES, Marcelo Pereira. Fatores motivacionais que influenciam no desempenho do trabalho exercido pelos policiais militares da $1^{\circ} \mathrm{CPM}$ do $8^{\circ}$ Batalhão de Polícia-Salgueiro/PE. Revista hum@nae, v. 12, n. 2, p. 1-19, 2018.

GIL, Antonio Carlos. Gestão de pessoas: enfoque nos papéis profissionais. 1. Ed. 12 reimpressão. São Paulo: Atlas, 2012.

GIL, Antônio Carlos. Métodos e técnicas de pesquisa. 6. ed. São Paulo, 2012.

GONÇALVES, Ana Paula Vieira; PROBST, Melissa. Gestão de Pessoas. Maiêutica-Estudos Contemporâneos em Gestão Organizacional, v. 4, n. 1, p. 57-64, 2016.

GONÇALVES, Elisa Pereira. Conversas sobre iniciação à pesquisa científica. 4. ed. Campinas, SP: Editora Alínea, 2007.

HANASHIRO, Darcy Mitiko Mori; TEIXEIRA, Maria Luisa Mendes; ZACCARELLI, Laura Menegon. Gestão do Fator Humano: uma visão baseada em stakeholders. São Paulo: Saraiva, 2007.

JESUS, Renata Gomes de. Comprometimento organizacional: um estudo de suas relações com percepção de gestão de pessoas e percepção de justiça oranizacional. Disponível em: https://repositorio.ufba.br/ri/bitstream/ ri/23558/1/Renata\%20Gomes\%20de\%20Jesus.pdf. Acesso em: 21 out. 2018.

LAKATOS, Eva Maria; MARCONI, Marina Andrade. Metodologia Científica. 6. ed. São Paulo: Atlas, 2011.

MARTINS, Lara Amabile et al. A influência da política de recompensas sobre os colaboradores em uma empresa de tecnologia de Florianópolis. 2017. Disponível em: https://repositorio.ufsc.br/bitstream/ 
handle/123456789/181632/A_influ\%C3\%AAncia\%20da_Pol\%C3\%ADtica de_Recompensas_sobre_os_colaboradores_de uma_empresa_de tecnologia 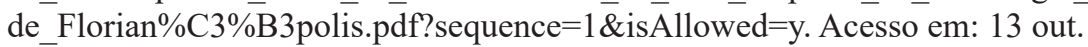 2018 .

MATOS, Rute Soraia Tomé de. O impacto do sistema de produção na competitividade no setor vitivinícola. 2018. Tese de Doutorado. Instituto Politécnico de Setúbal. Escola Superior de Ciências Empresariais. Disponível em: https://comum.rcaap.pt/bitstream/10400.26/20744/1/ rutematos_150327024_MCE_vers\%C3\%A3ofinal_Janeiro2018.pdf. Acesso em: 20 out. 2018.

MENDES, Monique Silveira. Fatores motivacionais em uma organização do setor da saúde: um estudo dos planos de benefícios de um hospital do sul de Santa Catarina. 2018. Disponível em: http://repositorio.unesc.net/ bitstream/1/5634/1/MoniqueMendes.pdf. Acesso em: 15 out. 2018.

MONTEIRO, Adara Isis Brito. NASCIMENTO, Mauro Athayde Campos. Gestão de Pessoas em Micro e Pequenas Empresas: um estudo de caso em uma empresa do setor de restaurantes em Belém-PA. In: Anais do Colóquio Organizações, Desenvolvimento e Sustentabilidade - CODS, 7., 2016, Anais eletrônicos [...]. 2016. Disponível em: http://revistas.unama.br/index.php/ coloquio/article/view/459/pdf. Acesso em: 15 out. 2018.

\section{MOREIRA, Jaciele Negrette. et al. Subsistemas de Gestão de Pessoas na Universidade Regional do Noroeste do Estado do Rio Grande do Sul-} UNIJUİ. Disponível em: https://publicacoeseventos.unijui.edu.br/. Acesso em: 21 out. 2018.

NYARADI, Lívia Ventura. Gestão de pessoas: um estudo sobre os meios de hospedagem da Ilha de Paquetá. 2017. Disponível em: https://app.uff.br/riuff/ bitstream/1/4900/1/Livia\%20Ventura\%20Nyaradi.pdf. Acesso em 28 out. 2018.

PORTELLA, Carlos Eduardo Miranda; DIAS, Cristiane. Estudo das Competências Essenciais dos Profissionais da Produção e Gestores de Uma Empresa do Agronegócio no Sul de Santa Catarina. In: Anais do Workshop de Administração. 2017. Anais Eletrônicos [...]. 2017. Disponível em: http:// periodicos.unesc.net/workshopadm/article/view/3504/3258. Acesso em: 21 out. 2018. 
RIBEIRO, Alexis Renan Silva; MARTINS, Pablo Luiz; NETA, Maria do Carmo Santos. Metas organizacionais e gestão estratégica de pessoas: estudo de caso em uma instituição financeira. Revista de Carreiras e Pessoas (ReCaPe), v. 7 , n. 2, p. 544-563, 2017.

ROESCH, S. M. A. Projetos de estágio e de pesquisa em administração: guia para estágios, trabalhos e conclusão, dissertações e estudos de caso. 3. ed. São Paulo: Atlas. 2010.

ROMAN, Darlan José. et al. Fatores de competitividade organizacional. BBR Brazilian Business Review, v. 9, n. 1, p. 27-46, 2012.

ROSA, Patrícia Alves da. Teoria e prática na administração de recursos humanos. 2017. Disponível em: http://repositorio.unesc.net/ bitstream/1/5447/1/Patr\%C3\%ADcia\%20Alves\%20da\%20Rosa.pdf. Acesso em: 21 out. 2018.

SANTOS, Joana Darc Estrela dos; JESUS, Silvia Manoela Santos de; FERREIRA, Thales Brandão. Inovação na Gestão de Pessoas: uma abordagem sobre inteligência organizacional. Revista de Negócios Uniages, v. 1, n. 1, p. 100-122, 2016.

SASTRE, Saul Marques. A espiritualidade como ferramenta de competitividade do século XXI. Revista Global Manager Edição Especial, v. 17, n. 2, p. 142163, 2017.

SILVA, Bruna Araújo Marques; MARCELINO, Mateus Zanin; SILVA, Monique Pinheiro Nogueira da. Gestão estratégica do capital humano para potencialização dos resultados nas organizações 2018. Disponível em: http://www.bibliotecadigital.funvicpinda.org.br:8080/jspui/ bitstream/123456789/553/1/SilvaMarcelinoSilva.pdf. Acesso em 15 out. 2018.

SILVA, Melissa Rodrigues Ataíde. Determinantes da retenção de empregados nas empresas no Brasil. 2017. Tese de Doutorado. Disponível em: https://comum.rcaap.pt/bitstream/10400.26/22221/1/Melissa\%20R\%20 Ataide\%20S\%20-\%20tese.pdf. Acesso em: 28 out. 2018.

SILVA, Danieli Portes da. Gestão de pessoas e produção: como o treinamento e desenvolvimento interferem na produção. Estudo de caso em uma fábrica de calçados. 2018. Disponível em: http://repositorio.upf.br/bitstream/riupf/1432/1/ SAR2018Danieli\%20Portes\%20da\%20Silva.pdf. Acesso em 10 out. 2018. 
SILVA, Andressa Hennig; FOSSÁ, Maria Ivete Trevisan. Análise de conteúdo: exemplo de aplicação da técnica para análise de dados qualitativos. Qualitas Revista Eletrônica, v. 17, n. 1, p. 1-14, 2015.

SOUSA, Luan Henrique; ANJOS, Mayara Abadia Delfino. Administração de crédito: um estudo de caso no interior de Minas Gerais. Revista GeTeC, v. 7, n. 17, 2018.

VARELA, Samira Helena Vieira. Sistema de recompensas e satisfação no trabalho-estudo de caso da Caixa Económica de Cabo Verde. 2017. Tese de Doutorado. Disponível em: https://repositorio.ipl.pt/bitstream/10400.21/8922/1/ DISSERTA $\%$ C3\%87\%C3\%83O $\% 20-\% 20$ SAMIRA $\% 20$ VARELA $\% 20-\% 20$ Vers\%C3\%A3o\%20definitiva.pdf. Acesso em: 28 out. 2018.

VIDAL, dos Santos Bianca. et al. Influências das políticas e práticas de gestão de pessoas na institucionalização da cultura de segurança. Production, v. 24, n. 1, p. 200-211, 2014.

YAMAUCHI, Fernanda. A gestão de pessoas no setor do agronegócio: um estudo sobre produtores de amendoim da região da Alta Paulista. 2017. Disponível em: http://hdl.handle.net/11449/151079. Acesso em: 18 out. 2018. 